\title{
In Situ Transfection by Controlled Release of Lipoplexes Using Acoustic Droplet Vaporization
}

\author{
Benjamin A. Juliar, Melissa M. Bromley, Alexander Moncion, Denise C. Jones, \\ Eric G. O'Neill, Christopher G. Wilson, Renny T. Franceschi, and Mario L. Fabiilli*
}

Localized delivery of nucleic acids to target sites (e.g., diseased tissue) is critical for safe and efficacious gene therapy. An ultrasound-based technique termed acoustic droplet vaporization (ADV) has been used to spatiotemporally control the release of therapeutic small molecules and proteins contained within sonosensitive emulsions. Here, ADV is used to control the release of lipoplex-containing plasmid DNA encoding an enhanced green fluorescent protein reporter-from a sonosensitive emulsion. Focused ultrasound $(3.5 \mathrm{MHz}$, mechanical index $(\mathrm{MI}) \geq 1.5)$ generates robust release of fluorescein (i.e., surrogate payload) and lipoplex from the emulsion. In situ release of the lipoplex from the emulsion using $\mathrm{ADV}$ (MI = 1.5, 30 cycles) yields a $55 \%$ release efficiency, resulting in $43 \%$ transfection efficiency and $95 \%$ viability with $\mathrm{C} 3 \mathrm{H} / 10 \mathrm{~T} 1 / 2$ cells. Without exposure to ultrasound, the release and transfection efficiencies are $5 \%$ and $7 \%$, respectively, with $99 \%$ viability. Lipoplex released by ADV retains its bioactivity while the ADV process does not yield any measureable sonoporative enhancement of transfection. Co-encapsulation of Ficoll PM 400 within the lipoplex-loaded emulsion, and its subsequent release using $A D V$, yield higher transfection efficiency than the lipoplex alone. The results demonstrate that ADV can have utility in the spatiotemporal control of gene delivery.

\section{Introduction}

Gene therapy could greatly impact the treatment of many intractable and refractory diseases, both acquired and genetic. However, despite numerous clinical trials, no gene therapy products have yet been approved in the United States by the Food and Drug Administration (FDA). ${ }^{[1]}$ One challenge in the clinical translation of gene therapy is the development of delivery vehicles for genes that are both safe and effective. The broad biodistribution of both viral and non-viral vectors can generate systemic side effects and elicit immunogenic responses. Therefore, restricting the spatial localization of vectors to target sites (e.g., cells, tissues, organs) is critical for therapeutic efficacy, while also minimizing transgene expression in non-target sites. At-site administration of vectors-either vascularly (e.g., intrarterial) or avascularly (e.g., intratumoral) - can achieve tight spatial localization, but this method is highly impractical for diffuse or inaccessible diseases. ${ }^{[2,3]}$

Both viral and non-viral vectors have been dosed systemically in clinical trials, with the latter vector accounting for $\approx 30 \%$ of trials. ${ }^{[4]}$ Despite lower gene transfer efficiencies, non-viral vectors have been pursued due to their lower immunogenicity, ability to deliver large genetic payloads, ease of synthesis, and cost-effectiveness. Transport of naked DNA across the cell membrane is extremely limited so complexation with a chemical vector is typically necessary. In the presented studies, nonviral DNA is complexed with cationic lipids to form lipoplexes that bind electrostatically to the cell membrane, are uptaken by endocytosis, and eventually are released from the endosome such that DNA is transported to the nucleus. ${ }^{[5-7]}$ When dosed intravenously, lipoplexes can display compromised stability, resulting from protein binding and degradation by nucleases; accumulation in the lung; and rapid clearance by the mononuclear phagocyte system. ${ }^{[8,9]}$ Chemical modification (e.g., pegylation, mannosylation) of lipoplexes can improve their pharmacokinetics, but spatial targeting remains a challenge. ${ }^{[10,11]}$ These limitations can ultimately impact the efficacy of non-viral gene delivery, localized uptake, and expression of the transgene. 
Ultrasound, which is used clinically for both diagnosis and treatment, has been investigated as one technique for improving targeted non-viral gene delivery. Ultrasound can be applied noninvasively with spatiotemporal control and focused with submillimeter precision to deeply located sites within the body. Lipoplexes have been externally conjugated to sonosensitive microbubbles, which are commonly used as contrast agents for diagnostic ultrasound. ${ }^{[12,13]}$ Ultrasound is then used to generate acoustic cavitation, which localizes the release of the conjugated lipoplex and its uptake via a non-endocytotic pathway. However, the circulation lifespan of microbubbles is short (i.e., $\approx$ minutes), which therefore can limit their utility in gene delivery. Additionally, the externally conjugated lipoplexes are not protected from the previously described destabilization mechanisms.

Sonosensitive emulsions are an alternative to microbubbles for ultrasound-based gene delivery. Possessing greater in vivo stability and longer circulation lifespans (i.e., $\approx$ hours), these sonosensitive emulsions possess a double emulsion structure of water-in-perfluorocarbon-in-water $\left(\mathrm{W}_{1} / \mathrm{PFC} / \mathrm{W}_{2}\right) \cdot{ }^{[14-16]}$ Watersoluble payloads (e.g., non-viral DNA) can be encapsulated into the $\mathrm{W}_{1}$ phase, rather than the conjugation of the payload to the exterior surface of the particle. The PFC phase inhibits payload diffusion and protects the payload from enzymatic degradation. Upon exposure to ultrasound above a threshold acoustic amplitude, the liquid PFC phase within the emulsion vaporizes into a gas, thus releasing the encapsulated payload.[17-19] This release process is termed acoustic droplet vaporization (ADV). ${ }^{[20]}$ The use of focused, megahertz frequency range ultrasound to generate ADV could facilitate spatially and temporally controlled gene delivery at deep locations within the body. Similar to microbubbles, emulsions can be targeted to vascular or extravascular sites (depending on the droplet size) by conjugating targeting moieties to the droplet surface. ${ }^{[21,22]}$

The presented studies investigate the encapsulation of plasmid DNA (pDNA) with an enhanced green fluorescent protein (eGFP) reporter, complexed in a lipoplex, in a sonosensitive double emulsion and its subsequent release using ADV. First, the encapsulation of the lipoplex was optically and electrophoretically evaluated to determine the effect of the emulsification process on the integrity of the pDNA. The acute cytotoxicity of the emulsion and one of its critical components, a fluorophilic block copolymer, were evaluated. Next, we interrogated a range of acoustic amplitudes to determine the release efficiency of a surrogate payload, fluorescein, from the emulsion using ADV. Based on this initial release experiment, a subset of acoustic conditions was selected to investigate the in situ transfection of cells using ADV-triggered release of lipoplex. The impact of ADV on pDNA bioactivity as well as lipoplex uptake (i.e., sonoporation) was also studied. Finally, the co-delivery of lipoplex and Ficoll PM 400 using ADV was investigated as a means of increasing transfection efficiency.

\section{Results and Discussion}

\subsection{Characterization of Emulsions}

Figure 1A displays a schematic of the double emulsion structure used to encapsulate the various payloads. Figure 1B contains an image of a lipoplex-loaded emulsion (LLE) containing Cy3labeled pDNA, which confirms the localization of lipoplex within the $\mathrm{W}_{1}$ droplets. Size distributions of the LLE and a representative image are shown in Figure 1C. The mean droplet diameter is $2.9 \mu \mathrm{m}$ with $3.1 \%$ (by number) of the droplets larger than $10 \mu \mathrm{m}$ in diameter. By comparison, Definity (Lantheus Medical Imaging) - a clinically approved, microbubble contrast agent has a mean particle diameter of 1.1-3.3 $\mu \mathrm{m}$ with $2 \%$ (by number) of the particles larger than $10 \mu \mathrm{m}$ in diameter. Among the emulsions containing different payloads, there were no statistically significant differences in mean droplet diameter or percent of payload encapsulated (Table 1).

The stability of the emulsion in Dulbecco's modified Eagle media (DMEM) and plasma is shown in Figure S1 of the Supporting Information. No statistically significant differences between DMEM and plasma were observed at any of the time points. For DMEM, there was a $10.5 \%$ decrease in droplet concentration when comparing $6 \mathrm{~h}$ versus $0 \mathrm{~h}$. Additionally in DMEM, there were small increases in the number percent of droplets greater than $10 \mu \mathrm{m}$ in diameter when comparing $6 \mathrm{~h}$ versus $0 \mathrm{~h}(5.4 \%)$ and $6 \mathrm{~h}$ versus $1 \mathrm{~h}(6.6 \%)$.

The acoustic attenuation of the emulsion diluted at $2 \%(\mathrm{v} / \mathrm{v})$ and $7 \%(\mathrm{v} / \mathrm{v})$ was $0.42 \pm 0.07$ and $0.67 \pm 0.11 \mathrm{~dB} \mathrm{~cm}^{-1} \mathrm{MHz}^{-1}$, respectively, in the range of 2.3-4.7 $\mathrm{MHz}$ (i.e., 69\% bandwidth); these dilutions were used in the fluorescein and lipoplex release studies, respectively. Thus, the diluted emulsion has a higher attenuation than water (i.e., $0.015 \mathrm{~dB} \mathrm{~cm}^{-1} \mathrm{MHz}^{-1}$ ) and is similar in attenuation to soft tissue (i.e., $\approx 0.5-0.7 \mathrm{~dB} \mathrm{~cm}^{-1} \mathrm{MHz}^{-1}$ ). ${ }^{[23,24]}$

\subsection{Cytotoxicity of Fluorosurfactants and Emulsion}

Formulation of the primary emulsion (i.e., $\mathrm{W}_{1} / \mathrm{PFC}$ ) requires a fluorophilic surfactant to stabilize the resulting water droplets. The acute cytotoxicity of the perfluoropolyether (PFPE)-polyethylene glycol (PEG)-PFPE (i.e., PFPE-PEG-PFPE) copolymer, used to stabilize the primary emulsion in all formulations, was compared to that of the perfluoropolyether with a terminal carboxylic acid group (PFPE-COOH) starting material. FC-770, a fluorophilic solvent, was used to dissolve the PFPE-COOH or PFPE-PEG-PFPE for the in vitro studies. Figure 2A shows the viability of $\mathrm{C} 3 \mathrm{H} / 10 \mathrm{~T} 1 / 2$ cells when incubated in FC-770 for $6 \mathrm{~h}$ compared to $6 \mathrm{~h}$ incubations in common aqueous buffers used in cell culture. Cellular metabolic activity was lower in FC-770 compared to complete media or DMEM, though not statistically different from Opti-MEM. Fully fluorinated liquids, such as Fluorinert or perfluorocarbons, are immiscible with aqueous solvents including hydrophilic nutrients required for cell growth. However, these fluorophilic liquids can dissolve extremely large amounts of oxygen. For example, the solubility of oxygen in FC-770 is $\approx 50 \%(\mathrm{v} / \mathrm{v})$ at $25^{\circ} \mathrm{C}$, which is $10-20 \times$ higher than cell culture media. ${ }^{[25,26]}$

The concentration dependent toxicity of PFPE-COOH and PFPE-PEG-PFPE is shown in Figure 2B. The experimental data were fit to a 4 parameter sigmoidal (i.e., logistical) function that can be found in a previous publication. ${ }^{[27]}$ Based on this regression, the half maximal inhibitory concentrations, in $\log (\mathrm{M})$, were $-4.3[-4.6,-4.0]$ and $-3.6[-3.9,-3.3]$ for PFPE-COOH and PFPE-PEG-PFPE, respectively. Thus, PFPE-PEG-PFPE is less 
A
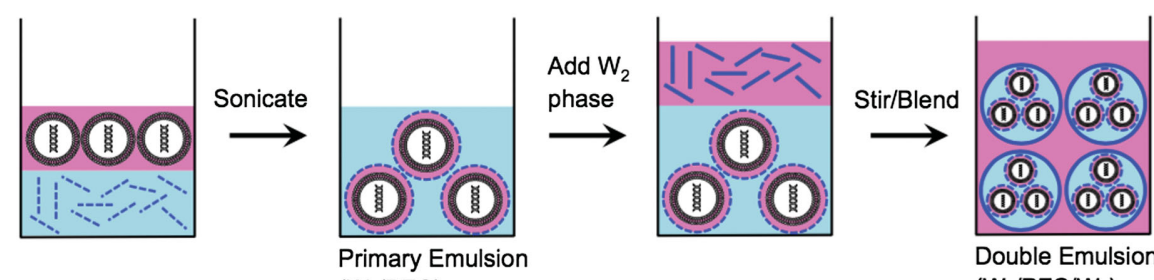

(1) Lipoplex $\left(\mathrm{W}_{1} / \mathrm{PFC}\right)$

Double Emulsion

$\left(\mathrm{W}_{1} / \mathrm{PFC} / \mathrm{W}_{2}\right)$

B

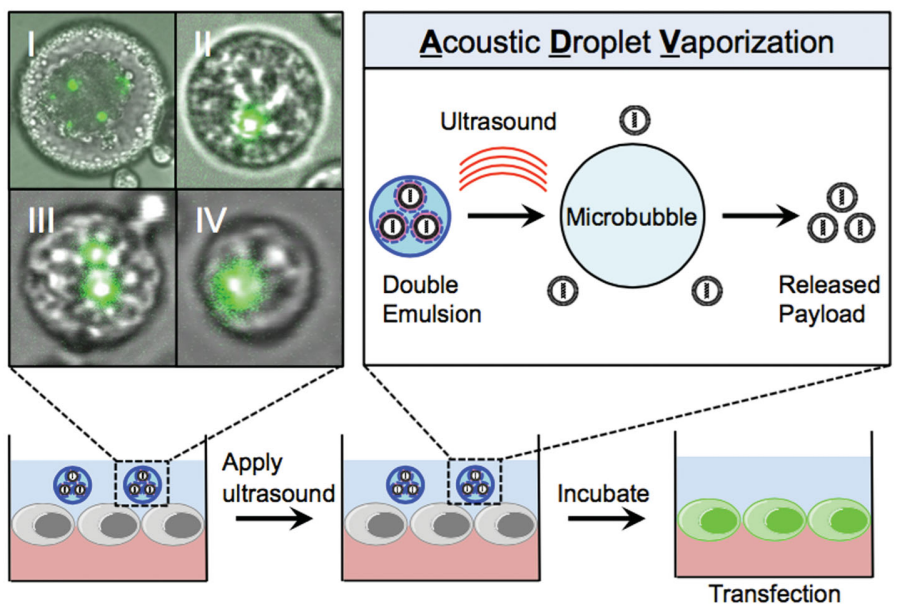

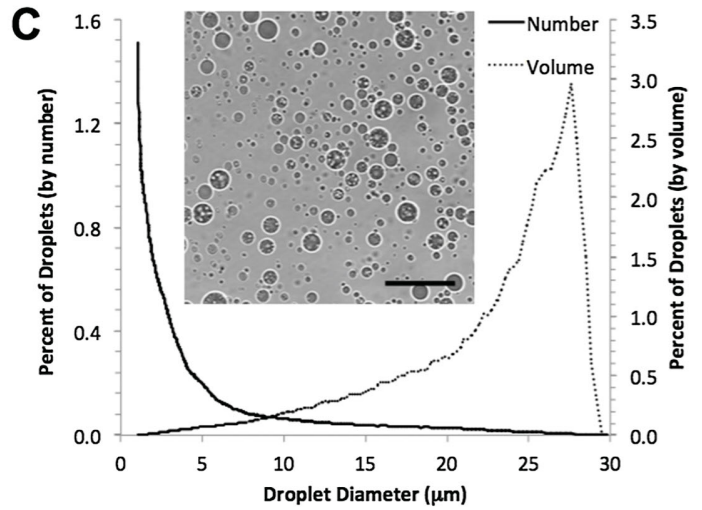

Figure 1. A) Schematic illustration of the formation of the water-in-perfluorocarbon-in-water $\left(\mathrm{W}_{1} / \mathrm{PFC} / \mathrm{W}_{2}\right)$ double emulsion. In this example, the primary emulsion (i.e., $W_{1} / P F C$ ) consists of a lipoplex payload contained within Opti-MEM $\left(W_{1}\right)$. The $W_{1}$ droplets are stabilized by a fluorosurfactant and dispersed within perfluoropentane. The primary emulsion is emulsified again in a solution of Polaxamer $188\left(\mathrm{~W}_{2}\right)$, thereby allowing the primary emulsion to be dispersed in aqueous solutions. B) Schematic illustration of lipoplex release using acoustic droplet vaporization. Lipoplex-loaded double emulsion was added to cells plated on fibrin gels and subsequently exposed to focused ultrasound to release the lipoplex. The top left inset shows confocal fluorescence images of double emulsion droplets containing lipoplexes (Cy3 labeled plasmid shown in green). The diameters of the droplets in images I-IV are 27,7.5, 5.1, and $2.5 \mu \mathrm{m}$, respectively. C) Number- and volume-weighted size distributions of a lipoplex-loaded double emulsion obtained using a Coulter Counter. The inset is an image of the double emulsion droplets (scale bar $=20 \mu \mathrm{m}$ ).

cytotoxic than PFPE-COOH. This finding is likely due to the ionizable carboxylic acid group in PFPE-COOH, which is not present in the PFPE-PEG-PFPE copolymer. Biomolecules such as proteins have been shown to interact with fluorosurfactants containing charged, terminal groups while no interactions were observed with non-ionizable, terminal groups. ${ }^{[28]}$

For all emulsions, the concentration of PFPE-PEG-PFPE in PFP was $1.0 \%(\mathrm{w} / \mathrm{w})$ or $1 \times 10^{-3} \mathrm{~m}$. Based on Figure $2 \mathrm{~B}$, this concentration of fluorosurfactant in FC-770 was cytotoxic. However, as can be seen in Figure 2C, when cells were incubated with blank emulsion diluted in DMEM, no cytotoxic effects were observed-even at $50 \%(\mathrm{v} / \mathrm{v})$ which yielded a monolayer of droplets on top of the plated cells. The presence of overlying DMEM (Figure 2C) likely mitigated the cytotoxicity of the

Table 1. Composition and characterization $(n=3)$ of double emulsions. All emulsions contained fluorosurfactant and Polaxamer 188 that stabilized the $\mathrm{W}_{1} / \mathrm{PFC}$ and $\mathrm{PFC} / \mathrm{W}_{2}$ interfaces, respectively.

\begin{tabular}{lccc}
\hline Payload(s) & $\begin{array}{c}\text { Aqueous component of } \\
W_{1} \text { and } W_{2} \text { phases }\end{array}$ & $\begin{array}{c}\text { Mean droplet } \\
\text { diameter }[\mu \mathrm{m}]\end{array}$ & $\begin{array}{c}\text { Percent } \\
\text { encapsulation }\end{array}$ \\
\hline None (i.e., blank) & PBS & $2.71 \pm 0.10$ & - \\
Fluorescein sodium & PBS & $2.73 \pm 0.30$ & $93.3 \pm 5.2$ \\
Lipoplex & Opti-MEM & $2.95 \pm 0.21$ & $93.7 \pm 4.2$ \\
Lipoplex + Ficoll PM 400 & Opti-MEM & $3.55 \pm 0.46$ & $95.0 \pm 0.6$ \\
\hline
\end{tabular}

PFPE-PEG-PFPE in the emulsion by decreasing the amount of fluorosurfactant in direct contact with the cells. Higher metabolic activity was observed in all test cases containing emulsion, relative to no emulsion. As mentioned previously, this could be due to oxygen loading within the perfluoropentane (PFP) of the emulsion. Fluorophilic liquids, either non-emulsified or emulsified, have been shown to enhance cell viability and proliferation when added to culture media or hydrogel matrices. ${ }^{[29,30]}$

\subsection{Stability of pDNA during Emulsification}

The stability of the pDNA and lipoplex following sonication, which is the method used to form the primary emulsion, was assessed using electrophoresis. As seen in Figure 3, the parental pDNA band is present in all sonicated samples. Fragmentation, as indicated by the diffuse smear of faster-migrating species, was observed with both the pDNA (Lane 2) and lipoplex (Lane 4) following sonication, with greater fragmentation occurring with pDNA. Since the samples were in an ice bath during sonication, the sample temperature did not exceed $10{ }^{\circ} \mathrm{C}$ during sonication. Thus, it is suspected that mechanical effects, such as hydrodynamic shear and cavitation impacted the integrity of the pDNA, rather than any thermal effects. Condensation of DNA using cationic agents can reduce fragmentation induced by sonication. ${ }^{[31]}$ It is possible that not all pDNA 

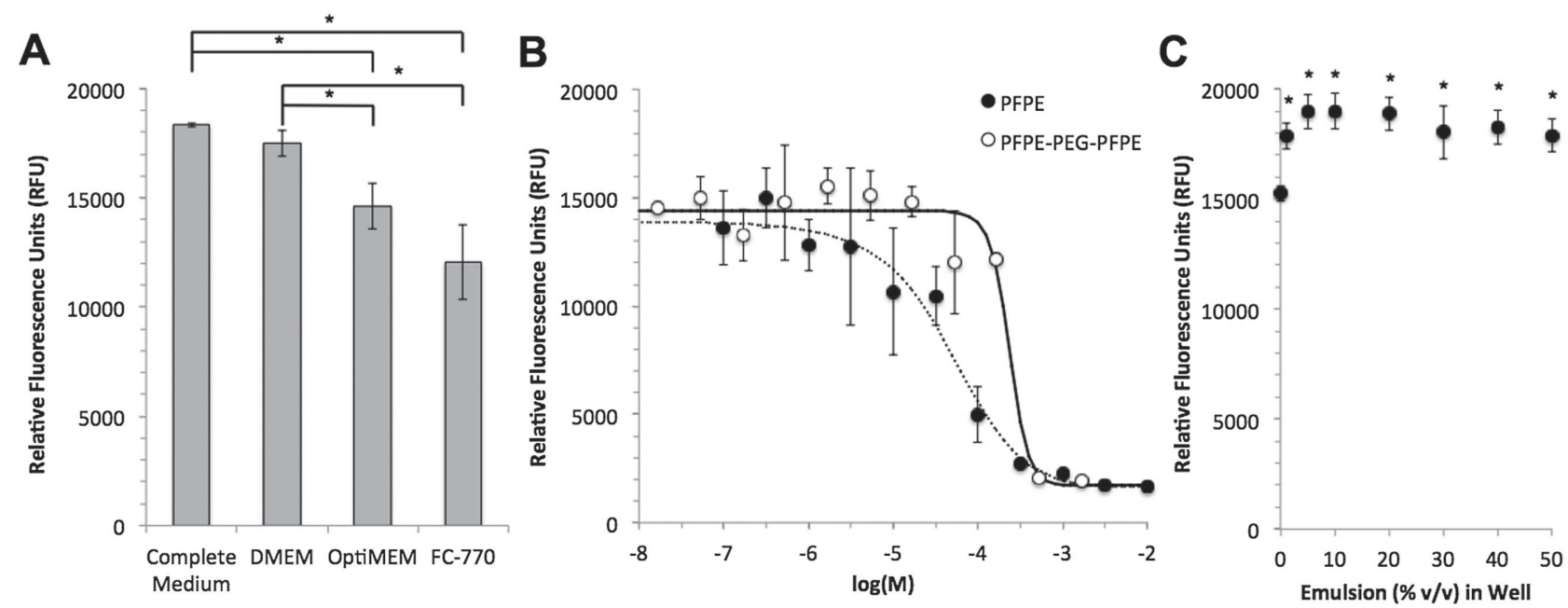

Figure 2. A) Metabolic activity $(n=5)$ of $\mathrm{C} 3 \mathrm{H} / 10 \mathrm{Tl} / 2$ cells incubated in various solvents for $6 \mathrm{~h}$. $* p<0.05$. B) Metabolic activity $(n=5)$ of $\mathrm{C} 3 \mathrm{H} / 10 \mathrm{Tl} / 2$ cells incubated for $6 \mathrm{~h}$ in FC-770 containing varying concentrations of PFPE-COOH or a PFPE-polyethylene glycol (PEG)-PFPE copolymer. C) Metabolic activity $(n=5)$ of $\mathrm{C} 3 \mathrm{H} / 10 \mathrm{~T} 1 / 2$ cells incubated for $6 \mathrm{~h}$ in blank double emulsion diluted in DMEM. $* p<0.05$ versus $0 \%(\mathrm{v} / \mathrm{v})$.

was complexed into lipoplexes (Lane 4), and thus the non-complexed pDNA was susceptible to fragmentation. No fragmentation was observed when the lipoplex was incorporated into the LLE via sonication and then subsequently released by ADV (Lane 5). The presence of two liquid phases (i.e., $\mathrm{W}_{1}$ and PFC) and fluorosurfactant may have lessened the impact of sonication on the pDNA during the formation of the LLE.

\subsection{Fluorescein Release by Ultrasound}

The relationship between the fraction of payload released from the emulsion and acoustic intensity was determined using an emulsion containing fluorescein sodium in the $\mathrm{W}_{1}$ phase. Figure 4 displays the sigmoidal release profile, with a mechanical index $(\mathrm{MI}) \geq 1.5$ yielding significant payload release relative to the no ultrasound condition (i.e., $\mathrm{MI}=0$ ). Spontaneous vaporization was not observed for any of the test conditions, thus indicating that the emulsion was thermally

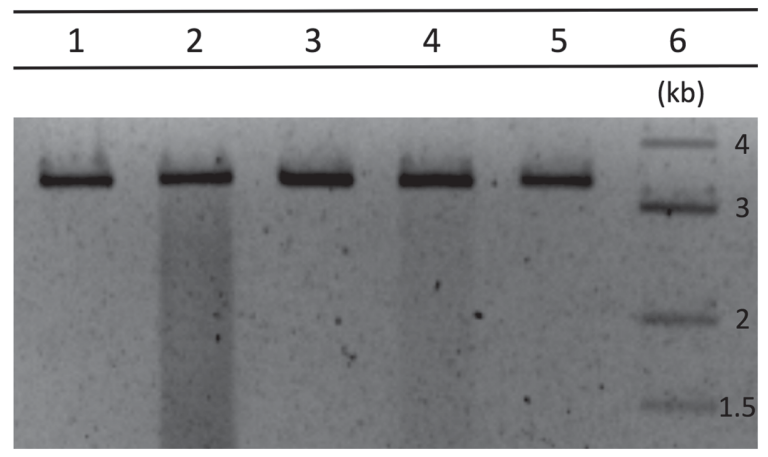

Figure 3. Gel electrophoresis confirming stability of plasmid after ultrasound exposures. Lane 1) pDNA; lane 2) sonicated pDNA; lane 3) lipoplex; lane 4) sonicated lipoplex; lane 5) emulsified lipoplex released by ultrasound $(3.5 \mathrm{MHz}$, mechanical index $(\mathrm{MI})=2.5,10 \mathrm{~Hz}$ pulse repetition frequency (PRF), 30 cycles); lane 6) $1 \mathrm{~kb}$ linear DNA ladder marker. The mass of pDNA was equivalent in all lanes. stable at $37{ }^{\circ} \mathrm{C}$. Therefore, payload release at $\mathrm{MI}<1.5$ is likely due to outward diffusion of fluorescein from the emulsion. Based on the regression, half maximal payload release occurred at $\mathrm{MI}=1.46[1.37,1.55]$. For diagnostic ultrasound, the current limit set by the United States FDA for the MI, which is related to the acoustic intensity and a measure of the likelihood for mechanical bioeffects, is 1.9. ${ }^{[32]}$ Thus payload release from the emulsions can be triggered by acoustic intensities achievable by diagnostic ultrasound. Higher acoustic intensities (i.e., MI > 1.9) can be achievable clinically using systems designed for therapeutic ultrasound (e.g., high intensity focused ultrasound). ${ }^{[33]}$

Since the population of droplets within the emulsion is polydisperse (Figure 1C), the sigmoidal trend in payload release was expected. Previous studies have demonstrated an inverse trend between the acoustic intensity required for ADV (i.e., the ADV threshold) and droplet diameter. ${ }^{[34,35]}$ As the acoustic intensity increases above the ADV threshold, a larger fraction of the total droplet population can undergo ADV. At the highest acoustic intensity tested ( $\mathrm{MI}=2.8$ ), a fraction of unvaporized emulsion remained, as is evidenced by the incomplete release of fluorescein in Figure 4. Thus, the ADV threshold of these remaining, smaller sized droplets was above $\mathrm{MI}=2.8$. The generation of an emulsion with a monodisperse population of droplets would enable a steeper transition (i.e., a Heaviside step function) between the acoustic intensities that yield minimum versus maximum payload release. ${ }^{[36]}$

\subsection{In Situ Transfection}

As an initial study, the transfectability of $\mathrm{C} 3 \mathrm{H} / 10 \mathrm{~T} 1 / 2$ cells when incubated with varying concentrations of lipoplexes was determined (Figure 5A). A sigmoidal relationship was observed between the percent of cells transfected and the pDNA concentration. Cell adherence, a measure of cell density normalized relative to the sham condition (i.e., $0 \mu \mathrm{g}$ pDNA per well), as well as the percent of dead cells correlated inversely and directly, 


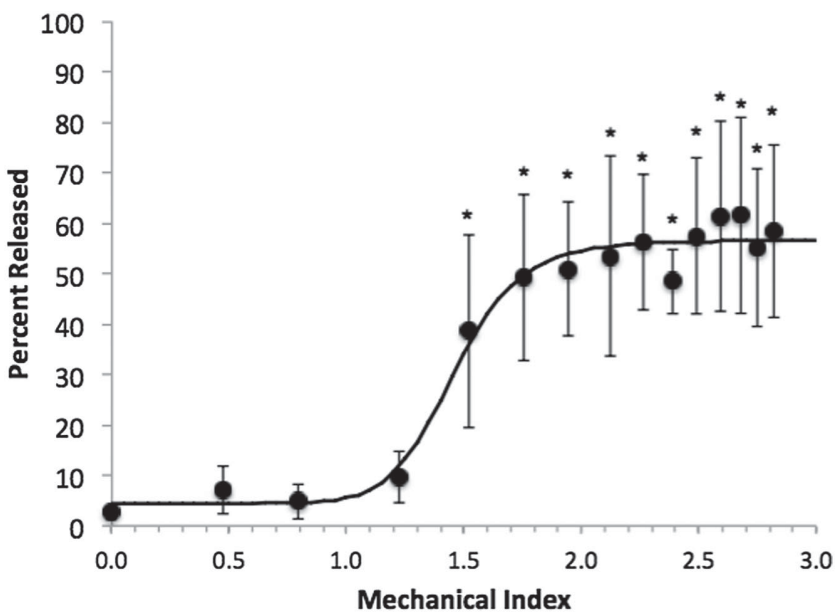

Figure 4. Release profile $(n=5)$ of fluorescein sodium, a small molecular weight surrogate payload, at varying acoustic amplitudes $(3.5 \mathrm{MHz}$, $10 \mathrm{~Hz}$ PRF, 10 cycles). $* p<0.05$ versus $\mathrm{MI}=0$.

respectively, with plasmid concentration. The cytotoxicity of lipoplexes at higher concentrations has been reported in the literature and is dependent on parameters such as the cell line as well as the lipid-pDNA molar charge ratio. ${ }^{[37-39]}$

Based on the release profile obtained in Figure 4, three acoustic amplitudes (i.e., $\mathrm{MI}=1.5,2.1$, and 2.5) were selected to investigate the release of pDNA from the LLE using ADV. Additionally two ultrasound pulse lengths ( 3 or 30 cycles) were also examined. Figure 5B shows the in situ transfection obtained using ADV. In the absence of ultrasound, $0.03 \pm 0.01 \mu \mathrm{g}$ of pDNA (or $4.7 \pm 1.0 \%$ of the total pDNA encapsulated) was released from the LLE. This percent of non-selective release was not statistically different than that observed for fluorescein. Exposure to ultrasound at MI $=1.5$ and 3 cycles yielded
$0.18 \pm 0.06 \mu \mathrm{g}$ pDNA released (i.e., $32.6 \pm 9.7 \%$ ). The other acoustic conditions yielded similar pDNA release in the range of $0.27 \pm 0.01$ to $0.31 \pm 0.03 \mu \mathrm{g}$ (i.e., $47.1-54.3 \%$ ). Therefore, ADV of the LLE significantly increase payload (i.e., pDNA) release compared to the no ultrasound condition. Additionally, as seen in Figure 4, the same acoustic amplitudes released $38.6-61.3 \%$ of fluorescein encapsulated in the emulsion. Thus, ADV-induced payload release from the emulsion appears to be independent of encapsulated payload. This suggests that the acoustically driven formation of gas nuclei within the droplets was not impacted by payloads with different molecular weights or other physical properties. For $\mathrm{MI}=1.5$, pDNA release increased as the burst length increased from 3 to 30 cycles. Since all samples were exposed to ultrasound for the same total time, the effective "on-time" for pulsed ultrasound at 30 cycles is $10 \times$ greater than at 3 cycles. At a fixed acoustic amplitude, the ADV threshold has been shown to correlate inversely with pulse duration, which would also support this trend at MI $=1.5 .{ }^{[40]}$

When exposed to LLE but not ultrasound, $7.4 \pm 2.7 \%$ of the cells were transfected. Exposure to ultrasound at $\mathrm{MI}=1.5$ and 3 cycles yielded $13.6 \pm 3.3 \%$ transfection whereas the level of transfection ranged from $42.9 \pm 8.0 \%$ to $54.0 \pm 8.5 \%$ for the other acoustic conditions. Thus ADV of the LLE significantly increases the level of transfection compared to the no ultrasound condition. Based on the sigmoidal regression in Figure 5A, the following levels of transfection were expected based on the mass of pDNA released: $4.0 \%$ for $0.03 \mu$ g (i.e., LLE but no ultrasound), $39.0 \%$ for $0.18 \mu$ g (i.e., LLE with MI $=1.5$ and 3 cycles), and 45.1 - 46.7\% for $0.27-0.31 \mu g$ (i.e., LLE with all other acoustic conditions). Thus, pDNA bioactivity does not appear to be affected by encapsulation and ADV-induced release.

Ultrasound alone at MI $=2.5$ and 30 cycles-the highest acoustic amplitude and longest burst length tested—did not cause a statistically significant decrease in cell adherence or
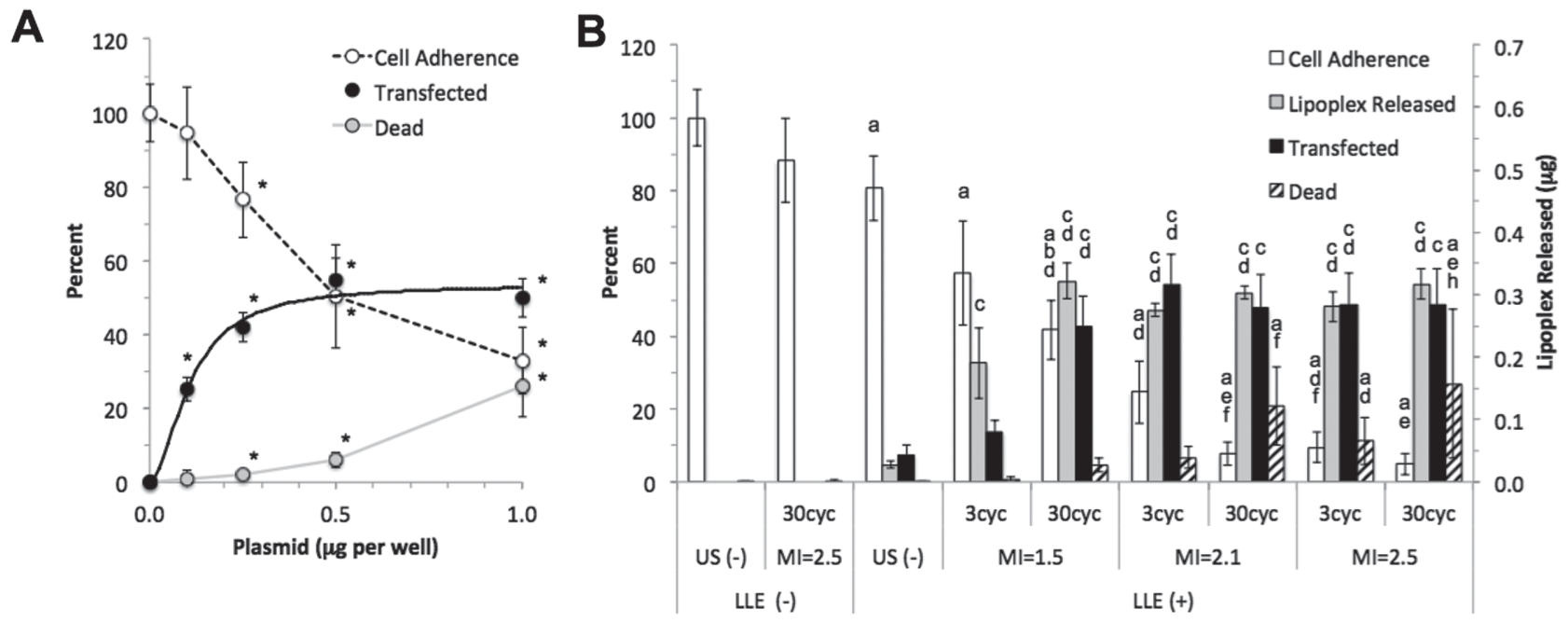

Figure 5. A) Transfection efficiency of $\mathrm{C} 3 \mathrm{H} / 10 \mathrm{Tl} / 2$ cells, plated on fibrin gels, following a $6 \mathrm{~h}$ incubation with lipoplexes $(1 \mu \mathrm{g}$ pDNA/2 $\mu \mathrm{L}$ Lipofectamine 2000). Percent cell adherence was normalized to the sham (i.e., $0 \mu \mathrm{g}$ plasmid). $* p<0.05$ versus $0 \mu \mathrm{g}$ plasmid. B) Cell adherence, percent transfected, and percent dead are shown for in situ ADV of lipoplex-loaded emulsion (LLE) using various acoustic parameters. The amount of lipoplex released is expressed in terms of percent and total $\mu \mathrm{g}$ released. Statistically significant differences $(p<0.05)$ are denoted by letters with the following comparisons: a versus (-LLE,-US); b versus (-LLE, MI = 2.5, 30 cyc); c versus (+LLE,-US); d versus (+LLE, MI = 1.5, 3 cyc); e versus (+LLE, MI = 1.5, 30 cyc); f versus $(+\mathrm{LLE}, \mathrm{MI}=2.1,3 \mathrm{cyc})$; $\mathrm{g}$ versus (+LLE,MI = 2.1, $30 \mathrm{cyc})$; $\mathrm{h}$ versus $(+\mathrm{LLE}, \mathrm{MI}=2.5,3 \mathrm{cyc}) . n=4$ wells with 3 fields of view per well. 
cell death when compared to the sham condition. Compared to Figure 5A, ADV of the LLE caused a greater decrease in cell adherence and increase in cell death for the same amount of pDNA released. As seen in the comparisons denoted in Figure 5B, an increase in the MI (at a fixed burst length) or an increase in the burst length (at a fixed MI) caused a decrease in cell adherence and increase in cell death. Based on the results, $\mathrm{ADV}$ at $\mathrm{MI}=1.5$ and 30 cycles or $\mathrm{MI}=2.1$ and 3 cycles enables maximization of transfection and minimization of cell loss/death. Using ultra high-speed microscopy, velocities of 5-25 $\mathrm{m} \mathrm{s}^{-1}$ have been observed as a droplet phase transitions into a gas bubble during ADV. ${ }^{[41,42]}$ Thus, the shear forces generated by ADV can cause deplating of adherent cells. ${ }^{[43]}$ Generating ADV with a higher ultrasound frequency (i.e., >3.5 MHz) or a single burst of ultrasound could decrease cytotoxicity by reducing the likelihood for mechanical effects such as inertial cavitation. ${ }^{[44]}$ Another potential strategy to minimize the bioeffects of ADV is to formulate the LLE with a PFC that has a boiling point lower than PFP (i.e., $29^{\circ} \mathrm{C}$ ). It has been previously demonstrated that the acoustic intensity required for ADV is correlated with the boiling point of the PFC within the emulsion. ${ }^{[45]}$ The impact of ADV on cellular viability can also be significantly decreased by co-encapsulating the emulsion and cells within a hydrogel scaffold, thereby presumably dampening the forces generated during $\mathrm{ADV} .^{[19,46]}$

\subsection{Impact of ADV on pDNA Bioactivity and Cellular Transfectability}

To further investigate the impact of ADV on the bioactivity of pDNA, a study was conducted where lipoplex was added to a sample of blank emulsion, either immediately before or after ADV (MI $=2.5$ and 30 cycles) of the blank emulsion. As seen in Figure 6, there was no difference in the level of transfection obtained with this ex situ condition compared to the positive control (i.e., lipoplex without emulsion or ultrasound). Additionally, there were no differences when adding the lipoplex before or after ADV. However, there was a decrease in cell adherence and increase in cell death that can be presumably attributed to the emulsion components, and not the acoustic exposure since ultrasound was applied in the absence of cells. This cellular bioeffect, observed when lipoplex was present, is in contrast to Figure 2C where blank emulsion (alone) did not generate cytotoxic effects. Additionally, as can be seen when comparing the results for $0.5 \mu \mathrm{g}$ pDNA per well for $1 \mathrm{~h}$ (Figure 6 ) or $6 \mathrm{~h}$ (Figure 5A) incubations, an increase in incubation time lead to an increase in the level of transfection and death as well as a decrease in cell adherence.

Ultrasound can generate transient pores within the cell membrane, thus facilitating uptake of both naked DNA and lipoplexes. ${ }^{[47,48]}$ This mechanism, termed sonoporation, enhances gene uptake via the interaction between ultrasound and microbubbles (i.e., acoustic cavitation). ${ }^{[49-51]}$ To determine if ADV could generate sonoporative effects that could increase the uptake of lipoplex, lipoplex and blank emulsion were added to plated cells either immediately before or $1 \mathrm{~h}$ after ADV (MI = 2.5 and 30 cycles) of the emulsion. A $1 \mathrm{~h}$ wait time was chosen since cell membranes typically reseal within minutes following sonoporation. ${ }^{[52]}$ As seen in Figure 6, there was no difference in the level of transfection obtained with this in situ condition compared to the positive control (i.e., lipoplex without emulsion or ultrasound). Thus, based on these experiments, ADV does not enhance lipoplex uptake. Sonoporation has been shown to increase the uptake of impermeable macromolecules as large as $2 \mathrm{MDa} .{ }^{[53]}$ Comparatively, the lipoplexes generated using Lipofectamine 2000 (LF2000) range in diameter from 0.76 to $1.0 \mu \mathrm{m}$, depending on the ratio of pDNA to LF2000. ${ }^{[54]}$ Therefore, two scenarios could explain the observed results. First, the experimental conditions did not generate pores within the cell membrane that were large enough for the lipoplex to enter the cell. Second, the experimental conditions did generate pores that were large enough for the lipoplex to enter the cell, but cell viability and thus transgene expression was compromised as a result of the large pore(s).

\subsection{Co-Delivery of Lipoplex and Ficoll Using ADV}

Ficoll PM 400 - a high molecular weight copolymer of sucrose and epichlorohydrin-is extremely hydrophilic, thus yielding highly viscous solutions at elevated concentrations. It was initially hypothesized that incorporating significant amounts of Ficoll into the $\mathrm{W}_{1}$ phase of the LLE, the media overlying the cells during the ultrasound exposure, or both would reduce the diffusion of lipoplex following release by ADV. The reduced mobility of the lipoplex would have enabled spatial localization of transfection in the 2D cell culture. However, our attempts at demonstrating localization using this approach were unsuccessful. It is likely that the ADV process enhanced the convection of the released lipoplex due to fluid movement generated by the droplet phase transition.

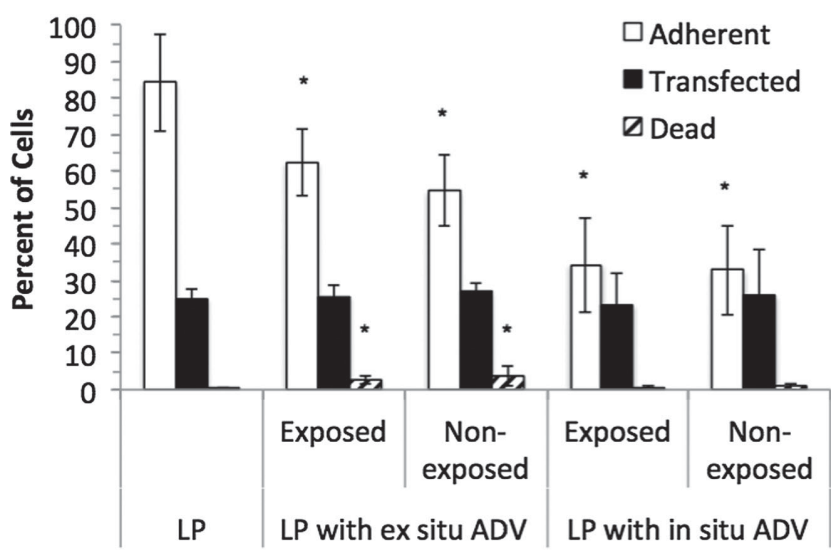

Figure 6. Cell adherence, percent transfected, and percent dead are shown for five different conditions in which lipoplex $(0.5 \mu \mathrm{g}$ plasmid per well) was incubated with $\mathrm{C} 3 \mathrm{H} / 10 \mathrm{~T} 1 / 2$ cells for $1 \mathrm{~h}$. LP: positive control (i.e., lipoplex) without emulsion or ADV. LP with ex situ ADV:ADV of a blank emulsion occurred in a separate plate, with lipoplex added either before (i.e., exposed) or after ADV (i.e., non-exposed). The resulting lipoplex-containing solution was then added to plated cells. LP with in situ ADV:ADV occurred in wells containing plated cells, with lipoplex added either before or after ADV. * $p<0.05$ versus LP. $\mathrm{n}=4$ wells with 3 fields of view per well. 
In an initial study without any emulsion or ultrasound, Figure 7A-C displays the effect of varying Ficoll concentrations on cell adherence, transfection, and death in the absence and presence of lipoplex. The inclusion of Ficoll did not affect cell adherence for either 0 or $1 \mu \mathrm{g}$ pDNA per well. The inclusion of Ficoll at $1 \%$ or $2 \%(\mathrm{w} / \mathrm{v})$ in the overlying media caused an increase in the level of achievable transfection, yielding $62.7 \pm 8.8 \%$ transfection with $2 \%$ Ficoll versus $48.6 \pm 4.6 \%$ transfection with $0 \%$ Ficoll. Therefore, Ficoll can enhance transfection even in the plateau region of the transfection dose response (Figure 5A). This phenomenon could be potentially useful with cell lines that are difficult to transfect. The inclusion of Ficoll alone did not affect cell death, though inclusion of lipoplex and $1 \%$ or $2 \%$ Ficoll caused an increase in cell death relative to the control (i.e., without lipoplex).

As seen in Table 1, inclusion of Ficoll in the $\mathrm{W}_{1}$ phase of the LLE did not affect the mean droplet diameter or percent payload encapsulated, relative to the LLE without Ficoll. Using an ex situ release setup (i.e., emulsion exposed to ultrasound in the absence of cells), ADV of LLEs with and without Ficoll yielded no difference in the amount of plasmid released (Figure 7D). However, cells incubated with releasate from the LLE with Ficoll exhibited greater transfection compared to LLE without Ficoll (i.e., $40.1 \pm 4.1 \%$ vs $35.9 \pm 3.0 \%$ ). A similar enhancement in transfection (i.e., $68.7 \pm 7.1 \%$ vs $60.4 \pm 7.4 \%$ ) was observed with an in situ release setup (Figure 8), where the LLEs with or without Ficoll were exposed to ultrasound in the presence of cells. Cell "islands" were generated by rastering the focused ultrasound beam in a defined pattern, which yielded release of the lipoplex from the LLE and loss of cell adherence in the periphery of the islands. Tight localization of ADV and the resulting spatial control of cell adherence could have utility in in vitro applications of tissue regeneration, for example, in the patterning of cell co-cultures. ${ }^{[37,55]}$

To the best of our knowledge, this is the first demonstration in the literature that Ficoll can be used to increase transfection.
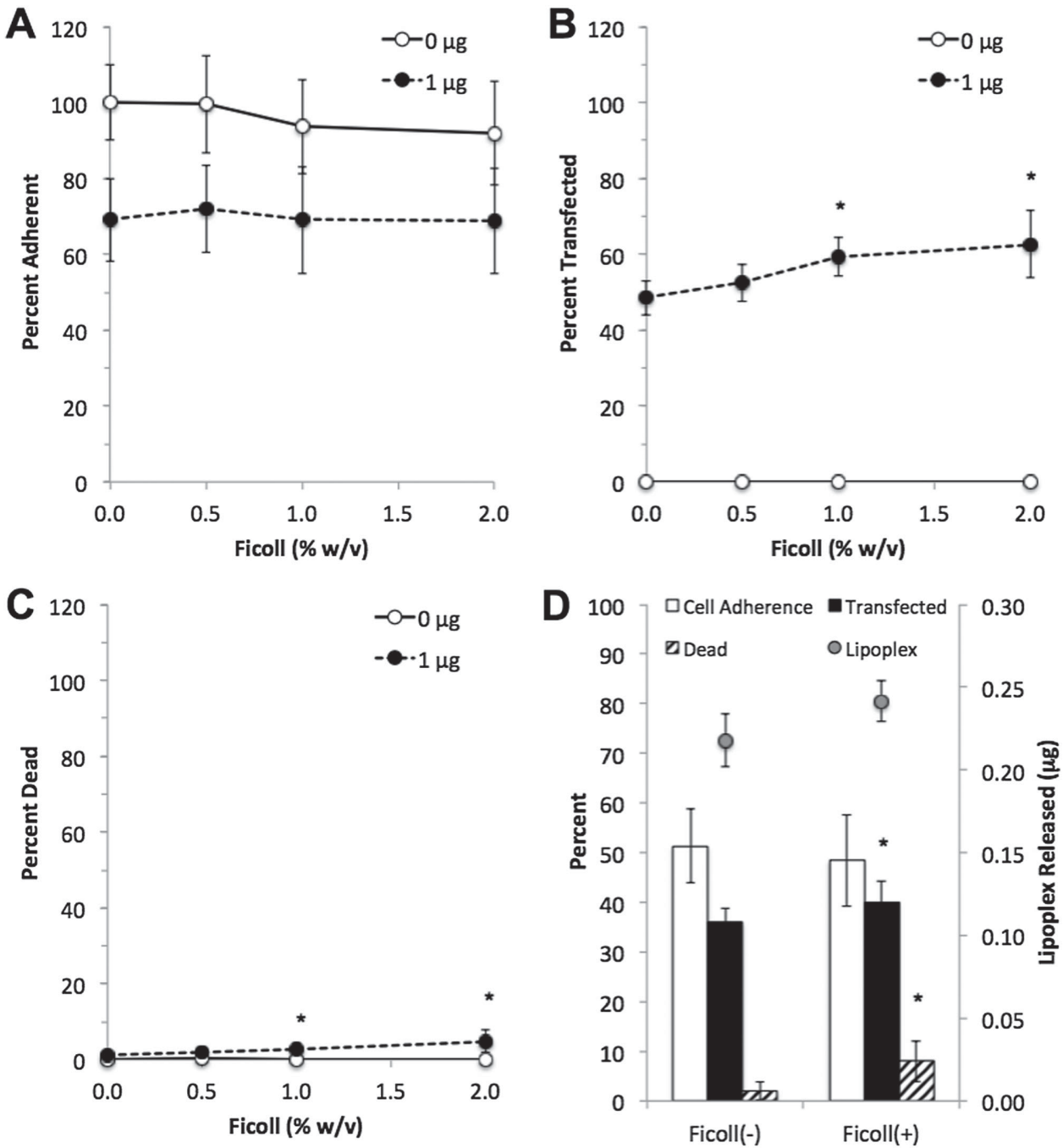

Figure 7. Effect of Ficoll PM 400 on A) percent cell adherence, B) percent cells transfected, and C) percent dead cells. Plated $\mathrm{C} 3 \mathrm{H} / 10 \mathrm{T1} / 2$ cells were incubated with lipoplex (0 or $1 \mu \mathrm{g}$ plasmid per well) for $6 \mathrm{~h}$. D) The inclusion of $16.7 \%(\mathrm{w} / \mathrm{w})$ Ficoll in the $\mathrm{W}_{1}$ phase of the LLE increased the percent of cells transfected. LLE with or without Ficoll was exposed to ultrasound in a separate plate, with the releasate being added to plated cells. $* p<0.05$ versus Ficoll (-). $n=4$ wells with 3 fields of view per well. 

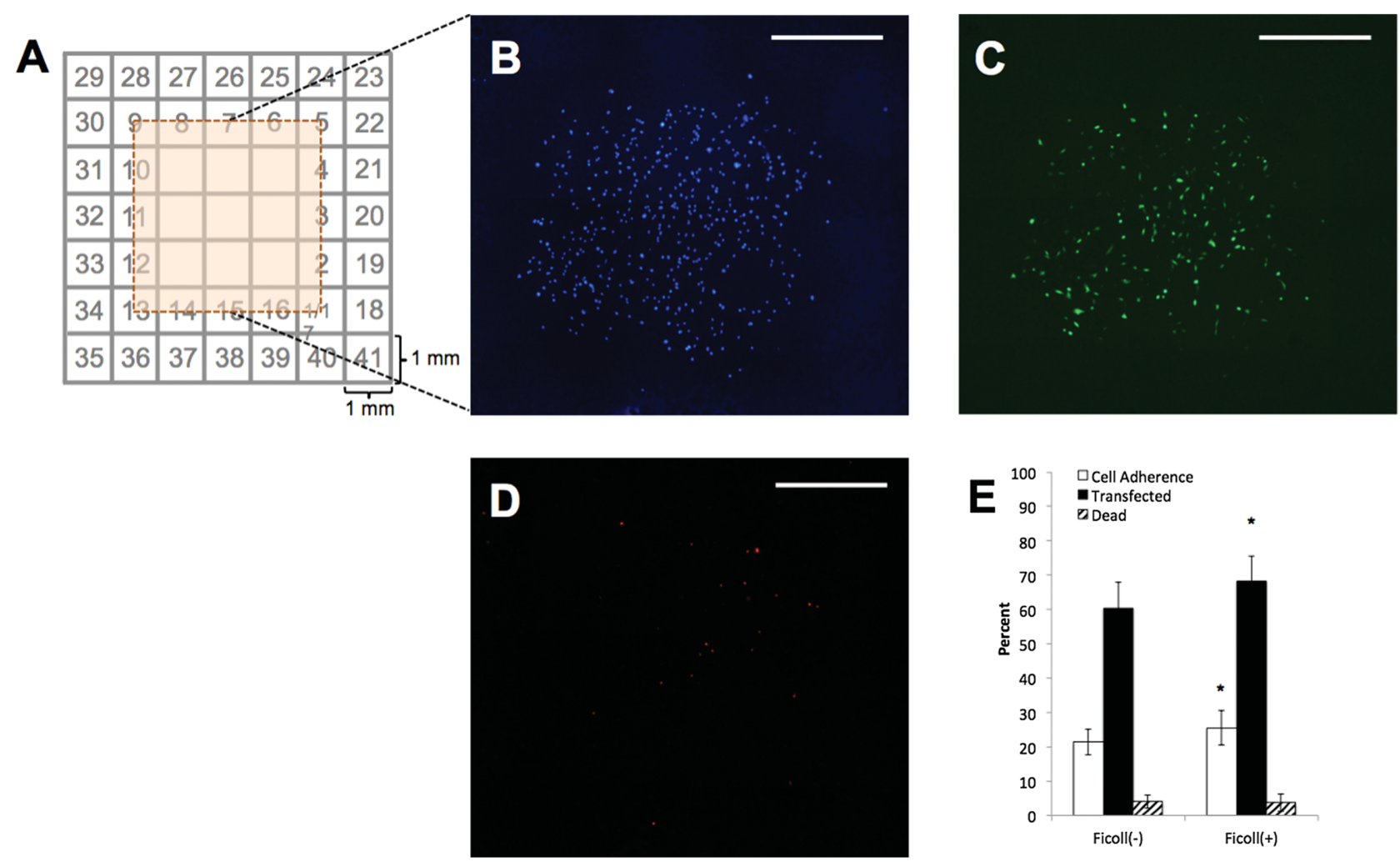

Figure 8. In situ ADV was used to release lipoplex from LLEs, with and without Ficoll, and selectively deplate cells, thus forming "islands". A) Schematic showing the ultrasound raster pattern used to form islands, with the exposure points numbered sequentially from 1 to 41 . LLE was added to the well before ultrasound exposure at points 1 and 9. A representative island was imaged for B) Hoescht, C) GFP, and D) propidium iodide. Scale bar: $1 \mathrm{~mm}$. E) Transfection statistics are shown for islands formed with the LLEs, with or without Ficoll. * $p<0.05$ versus Ficoll(-). $\mathrm{n}=4$ wells with 3 fields of view per well.

Since Ficoll is uncharged at biologically relevant $\mathrm{pH}$, it is unlikely to facilitate electrostatic binding of the lipoplex to the cell membrane or endosomal uptake. We hypothesize that Ficoll increases the release of lipoplexes from the endosomes via one of two mechanisms. Ficoll could permeabilize the endosomal membrane, similar to results obtained with glycerol or ethylene glycol. ${ }^{[56,57]}$ Alternatively, the hydrolysis of Ficoll could enhance osmotic swelling and eventual rupture of the endosome, similar to the proton sponge hypothesis of polyethylenimine-based polyplexes. ${ }^{[10]}$

\section{Conclusions}

This study demonstrates that pDNA, complexed in a lipoplex, can be stably encapsulated and released via ADV from a sonosensitive double emulsion. The pegylated fluorosurfactant used in stabilizing the double emulsion and the overall emulsion displayed favorable biocompatibility with $\mathrm{C} 3 \mathrm{H} / 10 \mathrm{~T} 1 / 2$ cells. Focused ultrasound at $3.5 \mathrm{MHz}$ and an $\mathrm{MI} \geq 1.5$ yielded robust release of encapsulated payloads, irrespective of payload size, from the emulsion. The bioactivity of lipoplex was unaffected by ADV release while the ADV process did not yield any measureable sonoporative enhancement of transfection. Ficoll PM 400 can be co-encapsulated with lipoplex in the double emulsion, yielding greater transfection than lipoplex alone. Additionally, cell adherence can be spatially patterned using ADV. The presented findings have broad applicability in the control of targeted gene delivery and future studies are aimed at the in vivo performance of these sonosensitive emulsions.

\section{Experimental Section}

Formulation and Characterization of Emulsion: The double emulsion $\left(\mathrm{W}_{1} / \mathrm{PFC} / \mathrm{W}_{2}\right)$ was prepared by modifying a previously published method. ${ }^{[16]}$ The primary emulsion $\left(W_{1} / P F C\right)$ was formed by dissolving a nonionic fluorosurfactant copolymer (PFPE-PEG-PFPE), synthesized from PFPE-COOH (Krytox 157 FSH, Dupont,Wilmington, DE, USA) and PEG (MW: $1000 \mathrm{~g} \mathrm{~mol}^{-1}$, Alfa Aesar, Ward Hill, MA, USA), at 1.0\% (w/w) in PFP (Strem Chemicals Inc., Newburyport, MA, USA). The PFP phase was combined with an aqueous $W_{1}$ phase, containing various payloads and solutes (described in later sections), at a volumetric ratio of 3.1:1. The phases were emulsified, while on ice, using an immersion sonicator (20 kHz, model Q55, QSonica, Newton, CT, USA) for $30 \mathrm{~s}$ in continuous mode. The resulting primary emulsion was added dropwise at a 1:2 volumetric ratio to a $1.0 \%(\mathrm{w} / \mathrm{v})$ solution of Poloxamer 188 (SigmaAldrich, St. Louis, MO, USA), dissolved in an aqueous buffer ( $\mathrm{W}_{2}$ phase, described in later sections), which was on ice and stirred at $700 \mathrm{rpm}$ for $2 \mathrm{~min}$. The resulting coarse double emulsion was blended using an immersion homogenizer (T10, IKA Works Inc., Wilmington, NC, USA) with $10 \mathrm{~s}$ on (speed 1), $30 \mathrm{~s}$ off, and $10 \mathrm{~s}$ on (speed 1). To minimize carryover of non-emulsified payload, the emulsion was allowed to settle and the supernatant was replaced with fresh $W_{2}$ phase. All emulsion 
compositions are listed in Table 1. For all experiments, the emulsions were used "as is" without any further processing or size separation.

Following formulation, each emulsion was sized using a Coulter Counter (Multisizer 4, Beckman Coulter Inc., Indianapolis, IN, USA) in the range of $1-30 \mu \mathrm{m}$. To assess stability, the emulsion was diluted at 7\% (v/v) in DMEM (Life Technologies, Grand Island, NY, USA) or ovine plasma and placed in a humidified incubator at $37^{\circ} \mathrm{C}$ with $5 \%$ carbon dioxide. The emulsion was periodically sampled and analyzed with a Coulter Counter. The acoustic attenuation of the emulsion, diluted at $2 \%$ $(\mathrm{v} / \mathrm{v})$ and $7 \%(\mathrm{v} / \mathrm{v})$ in phosphate buffered saline (PBS), was measured with a single-element transducer $(3.5 \mathrm{MHz}$, diameter: $19.1 \mathrm{~mm}$, focal length: $50.8 \mathrm{~mm}$, Olympus, Waltham, MA, USA) using a previously published method. ${ }^{[58]}$

Cell Culture: Cells of the mouse multipotent line $\mathrm{C} 3 \mathrm{H} / 10 \mathrm{~T} 1 / 2$, clone 8 (CCL-226, ATCC, Manassas, VA, USA) were cultured in complete media consisting of DMEM supplemented with $10 \%$ fetal bovine serum (Atlanta Biologicals Inc., Flowery Branch, GA, USA), $100 \mathrm{U} \mathrm{mL}^{-1}$ penicillin, and $100 \mu \mathrm{g} \mathrm{mL} \mathrm{L}^{-1}$ streptomycin. The cells, grown in a humidified incubator with $5 \%$ carbon dioxide, were continuously passaged to ensure confluence never exceeded $80 \%$. All experiments were performed with cells between passages $5-20$.

Cytotoxicity of Fluorosurfactant and Emulsion: Cells were plated in complete media in a 96-well plate (Costar, Corning Inc., Corning, NY, USA) at $10^{4}$ cells per well. This cell density was experimentally determined to yield the greatest assay sensitivity. The following day, the overlying media was removed and the cells were rinsed with DMEM. The cells were then incubated for $6 \mathrm{~h}$ with varying concentrations of fluorosurfactant-either PFPE-COOH or the PFPE-PEG-PFPE copolymer-dissolved in Fluorinert FC-770 (3M, St. Paul, MN, USA). Fluorinert FC-770 was used as the solvent since both fluorosurfactants are highly soluble in it. Additionally, the fluorophilic solvent has a relatively high boiling point $\left(95^{\circ} \mathrm{C}\right)$ and low vapor pressure. As controls, cells were also incubated in either complete media, DMEM, Opti-MEM (Life Technologies), or FC-770 alone. After $6 \mathrm{~h}$, the overlying media was removed, replaced with fresh complete media, and the cells were returned to the incubator. The following day, the viability of the cells was assessed using the alamarBlue assay (Invitrogen, Grand Island, NY, USA) according to the manufacturer's instructions. The fluorescence signal was analyzed with a plate reader (Ex: $560 \mathrm{~nm}$, Em: $585 \mathrm{~nm}$, SpectraMax M2e, Molecular Devices, Sunnyvale, CA, USA). An analogous cytotoxicity study was completed using varying concentrations of blank emulsion (i.e., without any payload) that contained Opti-MEM in the $\mathrm{W}_{1}$ phase and was dispersed in DMEM.

Ultrasound Setup for ADV: A calibrated, single-element transducerutilized in the attenuation measurements-was used to generate ADV and thus trigger the release of payloads encapsulated within the emulsions. The transducer was driven by a signal generated by a function generator (33500B, Agilent Technologies, Santa Clara, CA, USA) and amplified by a radiofrequency amplifier ( $55 \mathrm{~dB}, \mathrm{~A}-300$, Electronics \& Innovation, Rochester, NY, USA). Samples exposed to ultrasound were presented in a 24-well plate (Fisher Scientific, Pittsburgh, PA, USA) that was fixtured at the air-water interface of a temperature controlled (i.e., $37.0 \pm 0.5^{\circ} \mathrm{C}$ ), degassed water tank. The transducer was positioned below the plate such that the axial focus of the transducer was perpendicular with respect to each well. Pulse-echo, implemented using a pulser/receiver (5073PR, Olympus) and oscilloscope (HDO4934, Teledyne LeCroy, Chestnut Ridge, NY, USA), was used to finely adjust the axial focus of the transducer within each well. The transducer, which was connected to a micropositioning system, was rastered across each well to expose the contents to ultrasound.

Stability of Plasmid during Emulsification: Plasmid DNA (pDNA) with an enhanced green fluorescent protein reporter ( $p E G F P-C 1$, $4.7 \mathrm{~kb}$, Clontech, Mountain View, CA, USA) was prepared and purified by the University of Michigan Vector Core. Lipoplexes were generated by combining pDNA with LF2000 (Life Technologies), both diluted in Opti-MEM, at a ratio of $1 \mu \mathrm{g}$ pDNA per $2 \mu \mathrm{L}$ LF2000 according to the manufacturer's instructions. This ratio of pDNA to LF2000 was experimentally determined to maximize transfection efficiency while minimizing cytotoxicity. LLEs, containing lipoplexes as the payload and Opti-MEM as the solvent in the $W_{1}$ and $W_{2}$ phases, were formulated as described above. To visually confirm the incorporation of pDNA in the LLE, pDNA was covalently labeled with the Cy3 Label IT Tracker reagent (Mirus Bio, Madison, WI, USA) according to the manufacturer's instructions. LLE was formulated as previously described using the Cy3labeled pDNA. The resulting emulsion was imaged at the University of Michigan Microscopy \& Imaging Laboratory using an inverted confocal, fluorescence microscope (SP5X, Leica, Microsystems, Buffalo Grove, IL, USA) with a $100 \times$ objective.

Agarose gel electrophoresis was used to assess the stability of the pDNA during the emulsification process and subsequent ultrasoundtriggered release. Solutions of either pDNA or lipoplex were exposed to low frequency ultrasound (i.e., $20 \mathrm{kHz}$ ) generated by the immersion sonicator as previously described. Additionally, LLE was exposed to high amplitude ultrasound from the single element transducer $(\mathrm{MI}=2.5,10 \mathrm{~Hz}$ PRF, 30 cycles-where 1 cycle is equivalent to 1 acoustic wavelength) in order to release the encapsulated pDNA. The samples were analyzed using gel electrophoresis $(60 \mathrm{~V}, 2 \mathrm{~h})$, with a $1.0 \%$ $(w / v)$ agarose gel prepared in Tris/Borate/EDTA (TBE) buffer. Prior to loading onto the gel, the lipoplex samples were dissociated with heparin (final concentration: $7.5 \mathrm{U} \mathrm{mL} \mathrm{m}^{-1}$ ). The gel was subsequently stained with SYBR Gold Nucleic Acid Stain (Invitrogen) and imaged (Universal Hood II, Bio-Rad, Hercules, CA, USA). Control samples of non-sonicated plasmid and lipoplex as well as a $1 \mathrm{~kb}$ linear DNA ladder (N3232S, New England BioLabs, Ipswich, MA, USA) were also run on the gel. Equal masses of pDNA were loaded into each well of the gel.

Fluorescein Release Studies: To determine the acoustic amplitude required for payload release, emulsions were formulated as described above with fluorescein sodium (1 $\mathrm{mg} \mathrm{mL}^{-1}$, Sigma-Aldrich) as a payload and PBS as the solvent in the $W_{1}$ and $W_{2}$ phases. The emulsion was diluted at $2 \%(\mathrm{v} / \mathrm{v})$ in PBS and added to a 24-well plate. Each well was exposed to ultrasound at a constant acoustic amplitude for $1 \mathrm{~min}$. Following pulsed ultrasound exposure (10 Hz PRF, 10 cycles), the contents of each well were centrifuged to remove any remaining emulsion and the resulting supernatant was analyzed on a plate reader (Ex: $494 \mathrm{~nm}, \mathrm{Em}$ : 521). The encapsulated mass of fluorescein in the primary emulsion was determined by breaking the emulsion in a vacuum chamber at $5.8 \mathrm{kPa}$. The percent of fluorescein released at each acoustic amplitude was determined by normalizing the mass released via ultrasound to the mass released under vacuum. The encapsulation efficiency of the emulsion, defined as the fraction of payload in the primary emulsion (i.e., $\mathrm{W}_{1} / \mathrm{PFC}$ ) compared to the fraction in the primary emulsion plus the $\mathrm{W}_{2}$ phase, was also measured.

In Situ Transfection Using ADV: Fibrin gels were used as the substrate for cell culture since previous studies demonstrated that ADV could significantly deplate cells cultured on tissue culture plastic. ${ }^{[3,59]}$ Fibrin gels ( $5 \mathrm{mg} \mathrm{mL}^{-1}$ clottable protein, $0.36 \mathrm{~mL}$ total volume) were prepared in 24-well plates by combining bovine fibrinogen (Sigma-Aldrich), dissolved in FluoroBrite DMEM (Life Technologies) containing $100 \mathrm{U} \mathrm{mL}$ penicillin and $100 \mu \mathrm{g} \mathrm{mL}^{-1}$ streptomycin, with bovine thrombin $\left(2 \mathrm{U} \mathrm{mL} \mathrm{L}^{-1}\right.$, Thrombin-JMI, King Pharmaceuticals, Bristol, TN, USA). All solutions were degassed under vacuum prior to polymerization. Gels were allowed to polymerize for $30 \mathrm{~min}$ at room temperature prior to use.

Cells were subsequently plated on the gels at $1.2 \times 10^{4}$ cells per well in complete media (described previously) but containing FluoroBrite DMEM supplemented with $1 \times 10^{-3} \mathrm{M}$ sodium pyruvate and $4 \times 10^{-3} \mathrm{M}$ L-glutamine (Figure 1B). The cells were allowed to adhere to the gel overnight in an incubator. The following day, the overlying media was removed from the wells and replaced with FluoroBrite DMEM for 30 min prior to the addition of either lipoplexes $(0.1-1 \mu \mathrm{g}$ pDNA per well) or LLE ( $7 \% \mathrm{v} / \mathrm{v}$ per well). The wells containing LLE were exposed to pulsed ultrasound ( $10 \mathrm{~Hz}$ PRF) of varying amplitudes $(\mathrm{MI}=1.5$, 2.1 , or 2.5 ) and burst lengths (3 or 30 cycles) for $30 \mathrm{~s}$. The cells incubated for 6 hours with the lipoplex for all conditions before the overlying media was replaced with complete media.

The following day, the cells were stained with $16.2 \times 10^{-6} \mathrm{M}$ Hoechst 33342 (Invitrogen) and $15 \times 10^{-6} \mathrm{M}$ propidium iodide (Invitrogen). 
The cells were imaged with an inverted epifluorescent microscope (DMIL, Leica Microsystems) using a 10x objective to determine the total number of cells (i.e., Hoescht+), total number of cells transfected (i.e., eGFP+), and total number of cells dead (i.e., propidium iodide+) per field of view (FOV). The percent of cells that were transfected or dead was computed relative to the total number of cells in each FOV. Percent cell adherence was calculated as the average number of cells for an experimental condition divided by the average number of cells for the sham control (i.e., no lipoplex, LLE, or ultrasound).

The concentration of plasmid released from the LLE with various acoustic conditions was determined in an analogous experiment utilizing gels without plated cells. The released lipoplex was dissociated with heparin and then quantified using Quant-iT PicoGreen reagent (Invitrogen). ${ }^{[54]}$ To determine the loading of lipoplex within the LLE, the LLE was broken using an immersion sonicator (model 450, Branson, Danbury, CT, USA).

Effect of ADV on Plasmid Bioactivity and Transfection: Cells were plated on fibrin gels at $1.6 \times 10^{4}$ cells per well and allowed to adhere as previously described. The following day, the overlying media was replaced and the cells were incubated with lipoplex $(0.5 \mu \mathrm{g}$ pDNA per well, $1 \mathrm{~h}$ incubation) using the following ADV conditions. To determine the effect of ADV on the lipoplex, an ex situ setup was used where the lipoplex was added to a separate plate containing blank emulsion diluted in DMEM at $15 \%(v / v)$, either before (i.e., exposed) or after (i.e., nonexposed) the emulsion was exposed to pulsed ultrasound ( $M I=2.5$, $10 \mathrm{~Hz}$ PRF, 30 cycles). After ultrasound exposure, the contents of the wells were transferred to plated cells. To investigate the effect of ADV on cellular transfectability, an in situ setup was used where the blank emulsion was added to plated cells and ultrasound (MI $=2.1,10 \mathrm{~Hz}$ PRF, 30 cycles) was applied in a spotwise manner ( 5 spots spaced $1 \mathrm{~mm}$ apart). Before each ultrasound exposure, $15 \mu \mathrm{L}$ emulsion was added per spot to ensure sufficient emulsion for ADV. Lipoplex was added either immediately before (i.e., exposed) or $1 \mathrm{~h}$ after (i.e., nonexposed) the set of 5 exposures. Following the $1 \mathrm{~h}$ incubation for all groups, the overlying media was replaced and the cells were incubated overnight. The following day, the cells were stained/imaged as previously described.

Co-delivery of Lipoplex and Ficoll Using ADV: Cells were plated on fibrin gels at $1.6 \times 10^{4}$ cells per well and allowed to adhere as previously described. The cells were incubated with lipoplex $(1 \mu \mathrm{g}$ pDNA per well) diluted in DMEM containing $0 \%-2 \%$ (w/v) Ficoll PM 400 (GE Healthcare, Waukesha, WI, USA) for $6 \mathrm{~h}$. The overlying media was removed and the cells were stained/imaged the following day as stated previously.

An emulsion containing lipoplex and $16.7 \%(w / w)$ Ficoll as payload in Opti-MEM as the solvent in the $W_{1}$ phase was formulated as described above. To demonstrate ultrasound-triggered release of both lipoplex and Ficoll, two separate experiments were conducted. First, LLE or LLE containing Ficoll were diluted at $7 \%(v / v)$ in DMEM in a 24-well plate. The emulsions were exposed to ultrasound $(\mathrm{MI}=2.1$, $10 \mathrm{~Hz}$ PRF, 3 cycles) and the contents of the wells were centrifuged to remove any remaining emulsion. The concentrations of released plasmid in the releasates were determined using the PicoGreen assay and the releasates were then added to plated cells for $6 \mathrm{~h}$. The following day, the cells were stained/imaged as described previously. In a second experiment, LLE or LLE containing Ficoll were added to plated cells and ultrasound ( $\mathrm{MI}=2.5,10 \mathrm{~Hz} \mathrm{PRF}, 30$ cycles) was applied in a grid-like manner to release the encapsulated lipoplex and selectively deplate cells, thus generating cell "islands". The cells were incubated with the released lipoplex for $6 \mathrm{~h}$ and then stained/imaged the following day as stated.

Statistics: The data are expressed as the mean \pm standard deviation of measured quantities. The number of independent, replicate measurements ( $n$ ) is listed for each figure. The Tukey-Kramer method, evaluated in MATLAB, was used to determine statistically significant differences between multiple groups for the in situ transfection data, with differences deemed significant for $p<0.05$. Statistically significant differences of all other data sets were determined with a Student's $t$-test with differences deemed significant for $p<0.05$. The $95 \%$ confidence interval of calculated values is listed in the following format: $S\left[S_{L}, S_{H}\right]$, where $S$ is the average value, $S_{L}$ is the lower bound value, and $S_{H}$ is the upper bound value.

\section{Supporting Information}

Supporting Information is available from Wiley Online Library or from the author.

\section{Acknowledgements}

This work was supported by NIH grant R21AR065010 (MLF), the Basic Radiological Sciences Innovative Research Award (MLF), and the University of Michigan MCubed Program (RTF). A.M. was supported by the National Science Foundation Graduate Student Research Fellowship (Grant No. DGE 1256260). C.G.W. was supported by a postdoctoral training fellowship administered by NIDCR (T32DE007057-34). M.M.B., D.C.J., and E.G.O. were supported by funds from the Undergraduate Research Opportunity Program.

Received: January 5, 2016

Revised: March 15, 2016

Published online: May 18, 2016

[1] S. L. Ginn, I. E. Alexander, M. L. Edelstein, M. R. Abedi, J. J. Wixon, J. Gene Med. 2013, 15, 65.

[2] G. F. Zhang, J. J. Ludtke, C. Thioudellet, P. Kleinpeter, M. Antoniou, H. Herweijer, S. Braun, J. A. Wolff, Hum. Gene Ther. 2004, 15, 770.

[3] Y. Shirota, H. Shirota, D. M. Klinman, J. Immunol. 2012, 188, 1592.

[4] H. Yin, R. L. Kanasty, A. A. Eltoukhy, A. J. Vegas, J. R. Dorkin, D. G. Anderson, Nat. Rev. Genet. 2014, 15, 541.

[5] A. Elouahabi, J. M. Ruysschaert, Mol. Ther. 2005, 11, 336.

[6] C. T. de Ilarduya, Y. Sun, N. Duezguenes, Eur. J. Pharm. Sci. 2010, 40, 159.

[7] Z. U. Rehman, I. S. Zuhorn, D. Hoekstra, J. Controlled Release 2013, $166,46$.

[8] L. Xu, T. Anchordoquy, J. Pharm. Sci. 2011, 100, 38.

[9] M. Morille, C. Passirani, A. Vonarbourg, A. Clavreul, J. P. Benoit, Biomaterials 2008, 29, 3477.

[10] O. Boussif, F. Lezoualch, M. A. Zanta, M. D. Mergny, D. Scherman, B. Demeneix, J. P. Behr, Proc. Natl. Acad. Sci. USA 1995, 92, 7297.

[11] S. Kawakami, A. Sato, M. Nishikawa, F. Yamashita, M. Hashida, Gene Ther. 2000, 7, 292.

[12] M. L. De Temmerman, H. Dewitte, R. E. Vandenbroucke, B. Lucas, C. Libert, J. Demeester, S. C. De Smedt, I. Lentacker, J. Rejman, Biomaterials. 2011, 32, 9128.

[13] I. Lentacker, S. C. De Smedt, J. Demeester, V. Van Marck, M. Bracke, N. N. Sanders, Adv. Funct. Mater. 2007, 17, 1910.

[14] M. Zhang, M. L. Fabiilli, K. J. Haworth, J. B. Fowlkes, O. D. Kripfgans, W. W. Roberts, K. A. Ives, P. L. Carson, Ultrasound Med. Biol. 2010, 36, 1691.

[15] M. L. Fabiilli, M. R. Piert, R. A. Koeppe, P. S. Sherman, C. A. Quesada, O. D. Kripfgans, Contrast Media Mol. Imaging 2013, 8, 366 .

[16] M. L. Fabiilli, J. A. Lee, O. D. Kripfgans, P. L. Carson, J. B. Fowlkes, Pharm. Res. 2010, 27, 2753.

[17] C. H. Wang, S. T. Kang, Y. H. Lee, Y. L. Luo, Y. F. Huang, C. K. Yeh, Biomaterials 2012, 33, 1939.

[18] N. Rapoport, K. H. Nam, R. Gupta, Z. Gao, P. Mohan, A. Payne, N. Todd, X. Liu, T. Kim, J. Shea, C. Scaife, D. L. Parker, E. K. Jeong, A. M. Kennedy, J. Controlled Release 2011, 153, 4.

[19] M. L. Fabiilli, C. G. Wilson, F. Padilla, F. M. Martin-Saavedra, J. B. Fowlkes, R. T. Franceschi, Acta. Biomater. 2013, 9, 7399. 
[20] O. D. Kripfgans, J. B. Fowlkes, D. L. Miller, O. P. Eldevik, P. L. Carson, Ultrasound Med. Biol. 2000, 26, 1177.

[21] M. Javadi, W. G. Pitt, C. M. Tracy, J. R. Barrow, B. M. Willardson, J. M. Hartley, N. Tsosie, J. Controlled Release 2013, 167, 92.

[22] C. H. Wang, S. T. Kang, C. K. Yeh, Biomaterials 2013, 34, 1852.

[23] J. Krautkrämer, H. Krautkrämer, Ultrasonic Testing of Materials, Springer-Verlag, Berlin 1990.

[24] M. O. Culjat, D. Goldenberg, P. Tewari, R. S. Singh, Ultrasound Med. Biol. 2010, 36, 861.

[25] L. K. Ju, J. F. Lee, W. B. Armiger, Biotechnol. Progr. 1991, 7, 323.

[26] U. Kaisers, K. P. Kelly, T. Busch, Br. J. Anaesth. 2003, 91, 143.

[27] M. L. Fabiilli, K. J. Haworth, N. H. Fakhri, O. D. Kripfgans, P. L. Carson, J. B. Fowlkes, IEEE Trans. Ultrasonics. Ferr. Freq. Control. 2009, 56, 1006.

[28] L. S. Roach, H. Song, R. F. Ismagilov, Anal. Chem. 2005, 77, 785.

[29] A. Meyer, R. G. G. Condon, G. Keil, N. Jhaveri, Z. Liu, Y. S. Tsao, Biotechnol. Progr. 2012, 28, 171.

[30] E. Maillard, M. T. Juszczak, A. Clark, S. J. Hughes, D. R. W. Gray, P. R. V. Johnson, Biomaterials 2011, 32, 9282.

[31] M. L. Wu, S. S. Freitas, G. A. Monteiro, D. M. F. Prazeres, J. A. L. Santos, Biotechnol. Appl. Biochem. 2009, 53, 237.

[32] D. L. Miller, M. A. Averkiou, A. A. Brayman, E. C. Everbach, C. K. Holland, J. H. Wible, J. Wu, J. Ultras. Med. 2008, 27, 611.

[33] D. L. Miller, N. B. Smith, M. R. Bailey, G. J. Czarnota, K. Hynynen, I. R. S. Makin, J. Ultras. Med. 2012, 31, 623.

[34] K. C. Schad, K. Hynynen, Phys. Med. Biol. 2010, 55, 4933.

[35] P. S. Sheeran, V. P. Wong, S. Luois, R. J. McFarland, W. D. Ross, S. Feingold, T. O. Matsunaga, P. A. Dayton, Ultrasound Med. Biol. 2011, 37, 1518.

[36] T. D. Martz, P. S. Sheeran, D. Bardin, A. P. Lee, P. A. Dayton, Ultrasound Med. Biol. 2011, 37, 1952.

[37] P. Lei, R. M. Padmashali, S. T. Andreadis, Biomaterials 2009, 30, 3790.

[38] S. Yamano, J. S. Dai, A. M. Moursi, Mol. Biotechnol. 2010, 46, 287.

[39] A. Masotti, G. Mossa, C. Cametti, G. Ortaggi, A. Bianco, N. Del Grosso, D. Malizia, C. Esposito, Colloids Surf., B 2009, 68, 136.
[40] A. H. Lo, O. D. Kripfgans, P. L. Carson, E. D. Rothman, J. B. Fowlkes, IEEE Trans. Ultrasonics Ferr. Freq. Control. 2007, 54, 933.

[41] O. D. Kripfgans, M. L. Fabiilli, P. L. Carson, J. B. Fowlkes, J. Acoust. Soc. Am. 2004, 116, 272.

[42] O. Shpak, T. J. Kokhuis, Y. Luan, D. Lohse, N. de Jong, J. B. Fowlkes, M. L. Fabiilli, M. Versluis, J. Acoust. Soc. Am. 2013, 134, 1610.

[43] M. L. Fabiilli, K. J. Haworth, I. E. Sebastian, O. D. Kripfgans, P. L. Carson, J. B. Fowlkes, Ultrasound Med. Biol. 2010, 36, 1364.

[44] S. T. Kang, Y. C. Lin, C. K. Yeh, Ultrason. Sonochem. 2014, 21, 1866.

[45] P. S. Sheeran, S. H. Luois, L. B. Mullin, T. O. Matsunaga, P. A. Dayton, Biomaterials 2012, 33, 3262.

[46] A. Moncion, K. J. Arlotta, O. D. Kripfgans, J. B. Fowlkes, P. L. Carson, A. J. Putnam, R. T. Franceschi, M. L. Fabiilli, Ultrasound Med. Biol. 2016, 42, 257.

[47] M. T. Burgess, T. M. Porter, Ultrasound Med. Biol. 2015, 41, 2191.

[48] I. Lentacker, N. Wang, R. E. Vandenbroucke, J. Demeester, S. C. De Smedt, N. N. Sanders, Mol. Pharmaceutics 2009, 6, 457.

[49] Y. Zhou, J. M. Cui, C. X. Deng, Biophys. J. 2008, 94, L51.

[50] C. Y. Lai, C. H. Wu, C. C. Chen, P. C. Li, Ultrasound Med. Biol. 2006, 32, 1931.

[51] Z. Fan, D. Chen, C. X. Deng, J. Controlled Release 2013, 170, 401.

[52] Y. Zhou, J. Y. Shi, J. M. Cui, C. X. Deng, J. Controlled Release 2008, 126, 34.

[53] R. Karshafian, S. Samac, Ultrasonics 2010, 50, 691.

[54] C. Y. M. Hsu, H. Uludag, BMC Biotechnol. 2008, 8, 23.

[55] P. R. Baraniak, D. M. Nelson, C. E. Leeson, A. K. Katakam, J. L. Friz, D. E. Cress, Y. Hong, J. Guan, W. R. Wagner, Biomaterials 2011, 32, 3062.

[56] W. Zauner, A. Kichler, W. Schmidt, A. Sinski, E. Wagner, Biotechniques 1996, 20, 905

[57] W. Zauner, A. Kichler, W. Schmidt, K. Mechtler, E. Wagner, Exp. Cell Res. 1997, 232, 137.

[58] M. L. Fabiilli, R. A. Phanse, A. Moncion, J. B. Fowlkes, R. T. Franceschi, Ultrasound Med. Biol. 2016, 42, 824.

[59] R. Seda, D. S. Li, J. B. Fowlkes, J. L. Bull, Ultrasound Med. Biol. 2015, $41,3241$. 